\title{
Strong Ferromagnetic Exchange Coupling Mediated by a Bridging Tetrazine Radical in a Dinuclear Nickel Complex
}

\author{
Toby J. Woods, ${ }^{\dagger, \S, \perp}$ Heather D. Stout, ${ }^{\dagger, \perp}$ Brian S. Dolinar, ${ }^{\dagger}$ Kuduva R. Vignesh, ${ }^{\dagger}{ }^{\circledR}$ \\ Maria F. Ballesteros-Rivas, ${ }^{\dagger, \|}$ Catalina Achim, ${ }^{*},+$ and Kim R. Dunbar* ${ }^{*} \dagger$ (1) \\ ${ }^{\dagger}$ Department of Chemistry, Texas A\&M University, College Station, Texas 77842-3012, United States \\ ${ }^{\ddagger}$ Department of Chemistry, Carnegie Mellon University, Pittsburgh, Pennsylvania 15213, United States
}

\section{Supporting Information}

ABSTRACT: The radical bridged compound [(Ni(TPMA) $)_{2}-\mu$-bmtz $\left.{ }^{\bullet-}\right]\left(\mathrm{BF}_{4}\right)_{3} \cdot 3 \mathrm{CH}_{3} \mathrm{CN} \quad(\mathrm{bmtz}=3,6$-bis$\left(2^{\prime}\right.$-pyrimidyl $)-1,2,4,5$-tetrazine, $\mathrm{TPMA}=\operatorname{tris}(2$ pyridylmethyl)amine) exhibits strong ferromagnetic exchange between the $S=1 \mathrm{Ni}^{\mathrm{II}}$ centers and the bridging $S=$ $1 / 2 \mathrm{bmtz}$ radical with $J=96 \pm 5 \mathrm{~cm}^{-1}\left(-2 J_{\mathrm{Nirad}} S_{\mathrm{Ni}_{\mathrm{i}}} S_{\mathrm{rad}}\right)$. DFT calculations support the existence of strong ferromagnetic exchange.

$\mathrm{R}$ adical-bridged metal complexes with open-shell metal ions are interesting targets for applications in molecular magnetism. Whereas more commonly used closed-shell bridging ligands engage in indirect superexchange interactions between the metal centers, radical bridges facilitate direct exchange interactions, resulting in much stronger magnetic coupling. ${ }^{1}$ In the case of discrete molecules, the result is more well-isolated ground states, a situation that leads to higher effective barriers to magnetization reversal for SMMs. ${ }^{1 \mathrm{~b}, c, 2}$

One of the earliest examples of an organic radical-based magnet is $\mathrm{V}(\mathrm{TCNE}) \cdot n \mathrm{CH}_{2} \mathrm{Cl}_{2}(x \approx 2, n \approx 1 / 2$, TCNE $=$ tetracyanoethylene), which is extraordinary in that it exhibits spontaneous magnetization above room temperature. ${ }^{3}$ Another seminal discovery in the vein of radical chemistry is the realization of the first single chain magnet (SCM), [Co$\left.(\mathrm{hfac})_{2}(\mathrm{NITPhOMe}]\right)(\mathrm{hfac}=$ hexafluoroacetylacetonate, NIT$\mathrm{PhOMe}=4^{\prime}$-methoxy-phenyl-4,4,5,5-tetramethylimidazoline-1oxyl-3-oxide) in which the $\mathrm{Co}^{\mathrm{II}}$ units are connected via nitronyl nitroxide radicals. ${ }^{4}$ In addition, pioneering work involving semiquinone, ${ }^{5}$ nitroxide, ${ }^{6}$ and verdazyl ${ }^{7}$ radicals helped to pave the way to the current interest in the subject vis-à-vis design of new generations of SMMs. ${ }^{8}$ An excellent example of this concept is the postsynthetic reduction of neutral bridging ligands, one example of which is the report of a $2,2^{\prime}$-bipyrimidine radical that engenders strong magnetic coupling between lanthanide ions. ${ }^{2 a}$ Another important landmark is the isolation of [K(18-crown6) $]\left\{\left[\left(\mathrm{Me}_{3} \mathrm{Si}\right)_{2} \mathrm{~N}\right]_{2}(\mathrm{THF}) \mathrm{Gd}\right\}_{2}\left(\mu-\eta^{2}: \eta^{2}-\mathrm{N}_{2}\right)$ with a highly reduced dinitrogen bridge, a molecule that exhibits the strongest magnetic coupling between $\mathrm{Gd}^{\mathrm{III}}$ ions reported to date, viz., $J=$ $-27 \mathrm{~cm}^{-1}$. $^{\mathrm{b}}$

Our recent foray into $\mathrm{Ni}^{\mathrm{II}}$ chemistry is aimed at preparing polynuclear complexes with the tetrazine-based ligand 3,6-bis $(2$ 'pyrimidyl)-1,2,4,5-tetrazine (bmtz) in its stable radical anion form. ${ }^{9}$ The radical has been reported in compounds of $\mathrm{Cu}^{\mathrm{I}}$, ${ }^{10}$ $\mathrm{Ru}^{(0 / \mathrm{I} / \mathrm{II})}, 11 \mathrm{Re}^{\mathrm{I}, 12}$ and $\mathrm{Os}{ }^{(0 / / / \mathrm{II} / \mathrm{III}) 11}$ but had not yet been exploited in the area of molecular magnetism until our recent work. ${ }^{13}$ Herein, we report the synthesis and characterization of $\left[(\mathrm{Ni}(\mathrm{TPMA}))_{2}-\mu\right.$-bmtz $\left.{ }^{--}\right]\left(\mathrm{BF}_{4}\right)_{3} \quad\left(\mathbf{1} ;\right.$ bmtz $=3,6$-bis $\left(2^{\prime}\right.$-pyrimidyl)-1,2,4,5-tetrazine, TPMA = tris(2-pyridylmethyl)amine), which exhibits strong $\mathrm{Ni}^{\mathrm{II}}$-radical exchange coupling. In the course of submitting this paper, an article appeared in which the radical form of the bmtz ligand coordinated to four $\mathrm{Ni}^{\mathrm{II}}$ ions was reported. $^{14}$ The magnitude of the ferromagnetic coupling reported for this molecule is essentially the same as that found in this work for only two metal ions spanned by one bmtz radical.

Compound 1 was prepared by reacting a solution of in situ generated $\left[\mathrm{Ni}(\mathrm{TPMA})(\mathrm{solv})_{x}\right]\left(\mathrm{BF}_{4}\right)_{2}$ with the neutral form of bmtz (Figure 1). During the course of the reaction, the bmtz

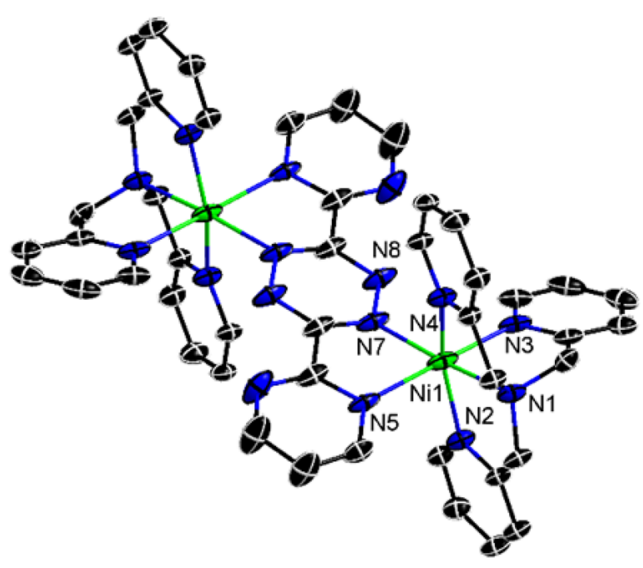

Figure 1. Thermal ellipsoid plot of the cationic unit of 1. Ellipsoids are drawn at the $35 \%$ probability level. $\mathrm{H}$ atoms omitted for the sake of clarity.

ligand is spontaneously reduced to the radical anion form. A perusal of the literature revealed that Kaim et al. had noted the same result in the absence of an obvious reducing agent. ${ }^{12}$ Higher yields of crystalline $\mathbf{1}$ were obtained by adding the reducing agent $\mathrm{Cp}_{2}{ }^{*} \mathrm{Co}$ to the reaction mixture. The cationic unit of 1 consists of two $[\mathrm{Ni}(\mathrm{TPMA})]^{2+}$ fragments bridged by a bmtz ligand in the radical anionic form. Only one of the $\mathrm{Ni}^{\mathrm{III}}$ ions is crystallographically unique and resides in a distorted octahedral coordination environment. The geometrical constraints of the ligand lead to $\mathrm{N}_{\mathrm{py}}-\mathrm{Ni}-\mathrm{N}_{\mathrm{amine}}$ angles for the $[\mathrm{Ni}(\mathrm{TPMA})]^{2+}$

Received: July 15, 2017 
fragment in the range $78.63(9)-82.3(1)^{\circ}$, much more acute than the expected $90^{\circ}$ angles for a bona fide octahedral coordination geometry. The $\mathrm{Ni}-\mathrm{N}$ bond lengths also vary significantly from $2.027(3)$ to 2.164(3) A. The distortion from an ideal octahedral geometry is best described as a meridional elongation. The Ni1N1, Ni1-N3, and Ni1-N5 bonds form one meridian of the octahedron spanning the bmtz pyrimidine ring, the bridgehead amine $\mathrm{N}$ atom of TPMA, and one of the pyridine rings of TPMA. The average bond length for the $\mathrm{Ni}-\mathrm{N}$ bonds in this meridian is $2.12 \AA$. The Ni1-N2, Ni1-N4, and Ni1-N7 bonds form the other meridian of the octahedron, with an average bond length of $2.07 \AA$ A. A list of selected bond distances and angles is provided in Table S2. Evidence for the radical anion oxidation state of the bmtz ligand is derived from the tetrazine $\mathrm{N}-\mathrm{N}$ bond lengths. At 1.383(4) $\AA$, the N7-N8a distance in $\mathbf{1}$ is consistent with previous reports of the radical anion state of bmtz and is significantly longer than the $1.33 \AA$ expected for the neutral form of the ligand. ${ }^{10}$ In addition, charge balance requires the cationic framework to have a +3 charge, consistent with two $\mathrm{Ni}^{\mathrm{II}}$ centers and one ligand radical. It is noted that $\pi-\pi$ stacking occurs between the pyridine rings of TPMA (Figure S1). The shortest atom-to-atom contact between these rings is 3.333(4) $\AA$, which is within the range of distances for such interactions. ${ }^{15}$ The intramolecular $\mathrm{Ni}-\mathrm{Ni}$ separation is 6.733(1) $\AA$, with the closest intermolecular Ni-Ni contact being 8.915(1) $\AA$.

A solution sample of $\mathbf{1}$ was characterized by electron paramagnetic resonance (EPR) under nonsaturating conditions (Figure 2). The spectrum shows features at $g=4.5$ and $g=9.9$,

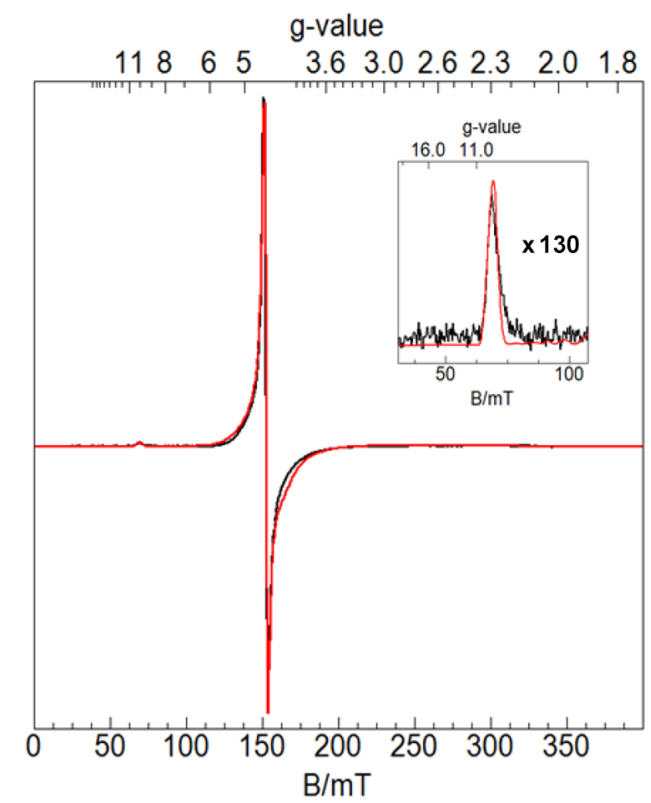

Figure 2. EPR spectrum of a $0.44 \mathrm{mM}$ sample of 1 in a 1:1.7 mixture of propionitrile and butyronitrile at $20 \mathrm{~K}$ (black). The inset is an enlargement of the $g=9.9$ excited state feature. The red line represents a SpinCount simulation for $S=5 / 2, g_{\text {iso }}=2.11,|D|=1 \mathrm{~cm}^{-1}$, and $E / D=$ 0.26 .

which correspond to the ground and excited $M_{S}$ states, respectively, of an effective $S=5 / 2$ ground state. Simulations using Spincount and the $S=5 / 2$ spin coupled representation yield $g_{5 / 2 \text {,iso }}=2.11$ and the zero field splitting $\left|D_{5 / 2}\right|<3 \mathrm{~cm}^{-1}$. High temperature studies to determine $D$ were hindered by signal broadening at $T>25 \mathrm{~K}$. The $S=5 / 2$ ground state arises from strong ferromagnetic coupling between each of the two
$\mathrm{Ni}(\mathrm{II})$ ions and the radical on the bmtz bridging ligand $\left(S_{\mathrm{Ni}}=1\right.$ and $S_{\text {rad }}=1 / 2$ ).

The static magnetic properties of a powder sample of 1 were measured from 2 to $300 \mathrm{~K}$ under various DC fields from 1,000 to 70,000 Oe (Figure 3). The magnetization versus field data at 1.8

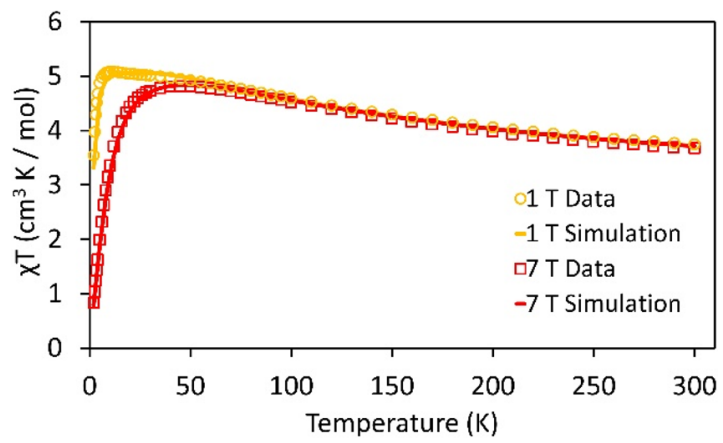

Figure 3. $\chi T$ vs $T$ plot 1 at $1 T$ (orange) and $7 T$ (red). Lines are simulations using the uncoupled spin Hamiltonian with $D_{\mathrm{Ni}}=4.7 \mathrm{~cm}^{-1}$, $E / D=0.25, g_{\text {iso, } \mathrm{Ni}}=2.35$, and $J=+96 \pm 5 \mathrm{~cm}^{-1}$.

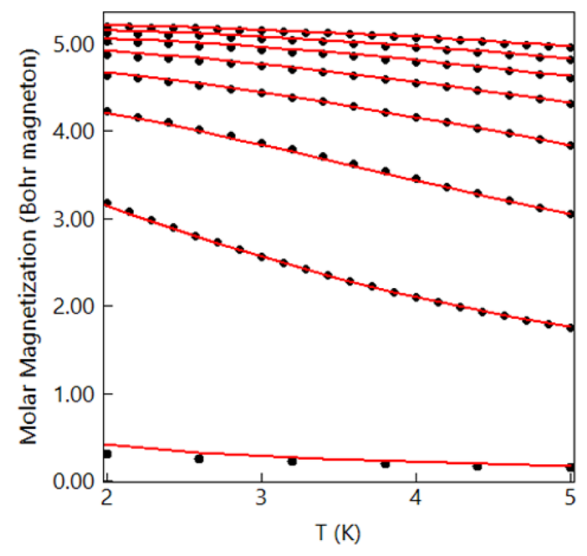

Figure 4. Molar magnetization data (dots) of 1 vs $T$ at $7 T$ to $0.1 T$. Simulations (black line) were applied using the $S=5 / 2$ Hamiltonian with $D_{5 / 2}=0.94 \mathrm{~cm}^{-1}, E / D=0.25$, and $g_{\text {iso }, 5 / 2}=2.28$. These parameters correspond to $D_{\mathrm{Ni}}=4.7 \mathrm{~cm}^{-1}$ and $g_{\mathrm{iso}, \mathrm{Ni}}=2.35$ in the uncoupled representation.

$\mathrm{K}$ (Figure 4) saturate at a value of $5 \mu_{\mathrm{B}}$, consistent with an $S=5 / 2$ ground state. Simulations of the molar magnetization at variable fields and low temperatures based on an $S=5 / 2$ spin coupled state result in $0.7<\left|D_{5 / 2}\right|<1 \mathrm{~cm}^{-1}$ and $2.26<g_{5 / 2 \text {,iso }}<2.34$. The $\left|D_{5 / 2}\right|$ value determined by analysis of the low temperature magnetization data is consistent with $\left|D_{5 / 2}\right|<3 \mathrm{~cm}^{-1}$ obtained from the EPR spectrum. The discrepancy between the $g_{5 / 2 \text {,iso }}$ determined by EPR and by magnetism is attributed to the differences between the samples being in solution and the solid state, respectively.

The $\chi T$ value of $3.68 \mathrm{~cm}^{3} \mathrm{~K} / \mathrm{mol}$ at $300 \mathrm{~K}$ is significantly higher than $2.80 \mathrm{~cm}^{3} \mathrm{~K} / \mathrm{mol}$ expected for an uncoupled system of two $\mathrm{Ni}^{\mathrm{II}}$ ions and one organic radical (Figure 3), which confirms the strong ferromagnetic coupling inferred from the EPR results. The $\chi T$ increases as the temperature decreases from $300 \mathrm{~K}$ and reaches a maximum of $4.82 \mathrm{~cm}^{3} \mathrm{~K} / \mathrm{mol}$ at $46 \mathrm{~K}$, consistent with a coupled $S=5 / 2$ ground state. Below $40 \mathrm{~K}, \chi T$ remains relatively constant until $15 \mathrm{~K}$, after which it decreases precipitously. 
High temperature magnetic data for 1 were analyzed with the uncoupled, three-spin representation (eqs S2 and S3). The D, E/ $D$, and $g$ parameters were extracted from simulations of the low temperature molar magnetization data at various fields (Figure 4) and the coupled spin Hamiltonian (eq S1). Subsequently, $J_{\mathrm{Ni} \text {-Rad }}$ was determined from simulations of the magnetic susceptibility data at $1 T$ and $7 T$ from 2 to $300 \mathrm{~K}$ using the uncoupled Hamiltonian (eq S3). The best-fit, assuming $g_{\text {rad }}=2.00$, yields $J_{\text {Ni-rad }}=+96 \pm 5 \mathrm{~cm}^{-1}\left(-2 J_{\mathrm{Ni} \text {-rad }} S_{\mathrm{Ni}} S_{\mathrm{rad}}\right)$, where $\left|D_{\mathrm{Ni}}\right|=5 \pm 1 \mathrm{~cm}^{-1}$ and $g_{\mathrm{Ni}, \text { iso }}=2.35$. Fitting of the $0.1 \mathrm{~T}$ susceptibility data (Figure S2) requires the addition of a weak mean field exchange coupling term due to intermolcular interactions and a $J_{\mathrm{Ni}-\mathrm{Ni}}$ term determined from DFT.

The EPR and magnetic susceptibity data indicate strong ferromagnetic coupling between the nickel and bmtz spin centers in the complex, in agreement with previous reports of strong FM coupling from $+94 \mathrm{~cm}^{-1}$ to $+186 \mathrm{~cm}^{-1}$ between nickel centers and $\mathrm{N}$-coordinating terminal radical ligands (Chart S1). ${ }^{14,16}$ In the present case, the sign of $J_{\text {Ni-radical }}$ is attributed to the orthogonality of the $\mathrm{e}_{\mathrm{g}}$ magnetic orbitals of $\mathrm{Ni}^{\mathrm{iI}}$ and the $\pi^{*}$ radical orbital of the ligand. To test this assertion, we conducted DFT and $a b$ initio calculations.

DFT computations using the B3LYP functional ${ }^{17}$ and TZVP basis sets were employed to calculate the $\mathrm{Ni}^{\mathrm{II}}-\mathrm{Ni}^{\mathrm{II}}$ and $\mathrm{Ni}^{\mathrm{II}}-\mathrm{bmtz}$ radical coupling. (See SI.) In accord with experimental data, the calculations predict strong ferromagnetic coupling between the $\mathrm{Ni}^{\mathrm{iI}}$ centers and the radical of $J_{\mathrm{Ni} \text {-rad }}=+95.8 \mathrm{~cm}^{-1}$ and weak AF coupling of $J_{\mathrm{Ni}-\mathrm{Ni}}=-0.7 \mathrm{~cm}^{-1}$. ${ }^{18}$ The calculations are consistent with the experimental data.

Strong ferromagnetic coupling between the $\mathrm{Ni}^{\mathrm{iI}}$ ions and the radical is rationalized on the basis of the orthogonality of the magnetic orbitals (Figure 5a). The calculation yields the a)

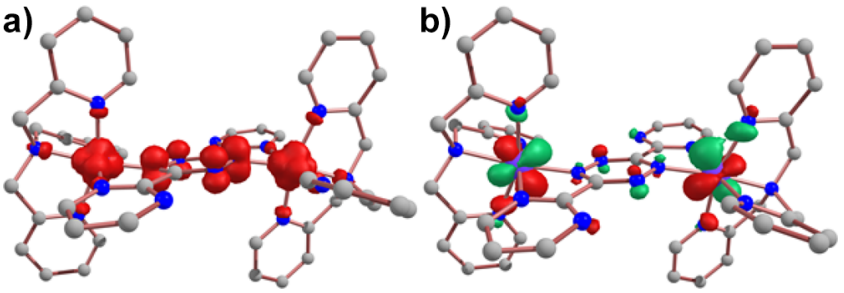

Figure 5. (a) Spin density for the $S=5 / 2$ ground state of $0.014 \mathrm{e}^{-} /$ bohr ${ }^{3}$. (b) Overlap of the $d_{x z}-d_{x z}$ orbitals of $\mathrm{Ni}^{\text {II }}$ ions. Green and red regions indicate positive and negative spin phases.

$\left[\left(\mathrm{d}_{x y}\right)^{2}\left(\mathrm{~d}_{x z}\right)^{2}\left(\mathrm{~d}_{y z}\right)^{2}\left(\mathrm{~d}_{x^{2}-y^{2}}\right)^{1}\left(\mathrm{~d}_{z^{2}}\right)^{1}\right]$ ground state for both $\mathrm{Ni}^{\mathrm{II}}$ ions. The weak antiferromagnetic $\mathrm{Ni}^{\mathrm{II}}-\mathrm{Ni}^{\mathrm{II}}$ interaction occurs through a small overlap between the $\mathrm{d}_{x z}-\mathrm{d}_{x z}$ of a pair of $\mathrm{Ni}(1)-\alpha$ and $\mathrm{Ni}(2)-\beta$ magnetic orbitals (Figure $5 \mathrm{~b}$ and Table S4 in the SI) through empty antibonding orbitals of bmtz. ${ }^{19}$

$A b$ initio calculations using CASSCF and NEVPT2 methods yielded values of 2.31 for the $g_{\mathrm{Ni}}$ parameter and $-6.4 \mathrm{~cm}^{-1}$ (CASSCF) and $-4.2 \mathrm{~cm}^{-1}$ (NEVPT2) for the ZFS parameter $D_{\mathrm{Ni}}$. The $g_{\mathrm{Ni}}$ value is in accord with the magnetism results; likewise the $D_{\mathrm{Ni}}$ values are in good agreement with the experimentally determined $|D|$ value of $4.7 \mathrm{~cm}^{-1}$. The CASSCF calculations predict the same orbital ordering as DFT methods with a small $d_{x y}-d_{x z} / d_{y z}$ energy gap and a significantly larger $d_{y z}$ $-\mathrm{d}_{x^{2}-y^{2}} / \mathrm{d}_{z}{ }^{2}$ gap (Figure S6). The radical ligand in the equatorial position stabilizes the $\mathrm{d}_{x y}$ orbitals. The magnitude of $D$ arises from three predominant, spin-conserved excitations: (i) $d_{x y} \rightarrow$ $\mathrm{d}_{x^{2}-y^{2}} / \mathrm{d}_{z^{2}}$ (Ex I), (ii) $\mathrm{d}_{x z} \rightarrow \mathrm{d}_{x^{2}-y^{2}} / \mathrm{d}_{z}{ }^{2}$ (Ex II) and (iii) $\mathrm{d}_{y z} \rightarrow \mathrm{d}_{x}{ }^{2}-y^{2} /$ $\mathrm{d}_{z}{ }^{2}$ (Ex III). ${ }^{20}$ Examination of the excitations indicates that the negative contribution to the $D$ value arises mainly from excitation I $\left(-27.7 \mathrm{~cm}^{-1}\right)$, whereas excitations II and III have positive contributions $\left(+15.8\right.$ and $\left.+7.0 \mathrm{~cm}^{-1}\right)$ to the total $D$ value; the result is a small, negative $D$ value.

The crystallographic, magnetic and EPR data presented in this paper indicate strong magnetic coupling between the spins of the radical bmtz ligand and of the $\mathrm{Ni}^{\mathrm{II}}$ centers, a finding corroborated by DFT calculations, the origin of which is the orthogonality of the bmtz SOMO and the $\mathrm{d}_{x^{2}-y^{2}}$ and $\mathrm{d}_{z}{ }^{2}$ orbitals of the $\mathrm{Ni}^{\mathrm{II}}$ centers.

\section{ASSOCIATED CONTENT}

\section{S Supporting Information}

The Supporting Information is available free of charge on the ACS Publications website at DOI: 10.1021/acs.inorgchem.7b01812.

Full details are provided for the synthesis, crystallography, magnetism, computational details, and cyclic voltammetry measurements (PDF)

\section{Accession Codes}

CCDC 1021285 and 1528867 contain the supplementary crystallographic data for this paper. These data can be obtained free of charge via www.ccdc.cam.ac.uk/data request/cif, or by emailing data request@ccdc.cam.ac.uk, or by contacting The Cambridge Crystallographic Data Centre, 12 Union Road, Cambridge CB2 1EZ, UK; fax: +44 1223336033.

\section{AUTHOR INFORMATION}

\section{Corresponding Authors}

*E-mail: achim@cmu.edu.

*E-mail: dunbar@chem.tamu.edu.

\section{ORCID}

Brian S. Dolinar: 0000-0002-8228-4590

Kuduva R. Vignesh: 0000-0002-0971-2990

Kim R. Dunbar: 0000-0001-5728-7805

\section{Present Addresses}

${ }^{\S}$ School of Chemical Sciences, University of Illinois at UrbanaChampaign, Urbana, IL 61801, United States

"Centro Conjunto de Investigacion en Quimica Sustentable, UAE Mex-UNAM (CCIQS), Carretera Toluca-Altacomulco, km 14.5, Toluca, Estado de Mexico, C.P. 50200, Mexico

\section{Author Contributions}

${ }^{\perp}$ These authors contributed equally.

\section{Funding}

This work was supported by the National Science Foundation under Grant No. CHE-1310574.

\section{Notes}

The authors declare no competing financial interest.

\section{ACKNOWLEDGMENTS}

T.J.W. thanks the Department of Energy Office of Science Graduate Fellowship Program made possible in part by the American Recovery and Reinvestment Act of 2009, administered by ORISE-ORAU under contract no. DE-AC05-06OR23100. M.F.B.-R. thanks the Instituto de Ciencia y Tecnología del Distrito Federal (ICyTDF) for fellowship support. H.D.S. and C.A. thank Dr. Michael Hendrich for the use of Spincount. K.R.D. gratefully acknowledges funding from the National Science Foundation (CHE-1310574) and the Robert A. Welch Foundation (A-1449). We would like to thank the HPRC at Texas A\&M University for providing computing resources. 


\section{REFERENCES}

(1) (a) Gatteschi, D.; Sessoli, R.; Villain, J. Molecular Nanomagnets; Oxford University Press, Inc.: New York, 2006. (b) Rinehart, J. D.; Fang, M.; Evans, W. J.; Long, J. R. Strong exchange and magnetic blocking in $\mathrm{N}_{2}{ }^{3-}$ radical-bridged lanthanide complexes. Nat. Chem. 2011, 3, 538542. (c) Rinehart, J. D.; Fang, M.; Evans, W. J.; Long, J. R. $\mathrm{A} \mathrm{N}_{2}{ }^{3-}$ Radical-Bridged Terbium Complex Exhibiting Magnetic Hysteresis at 14 K. J. Am. Chem. Soc. 2011, 133, 14236-14239. (d) Zhu, M.; Li, Y.-G.; Ma, Y.; Li, L.-C.; Liao, D.-Z. Unprecedented Nitronyl Nitroxide Bridged 3d-4f Complexes: Structure and Magnetic Properties. Inorg. Chem. 2013, 52, 12326-12328. (e) Fortier, S.; Le Roy, J.J.; Chen, C.-H.; Vieru, V.; Murugesu, M.; Chibotaru, L. F.; Mindiola, D. J.; Caulton, K. G. A Dinuclear Cobalt Complex Featuring Unprecedented Anodic and Cathodic Redox Switches for Single-Molecule Magnet Activity. J. Am. Chem. Soc. 2013, 135, 14670-14678. (f) Wu, J.; MacDonald, D. J.; Clerac, R.; Jeon, I.-R.; Jennings, M.; Lough, A. J.; Britten, J.; Robertson, C.; Dube, P. A.; Preuss, K. E. Metal Complexes of Bridging Neutral Radical Ligands: pymDTDA and pymDSDA. Inorg. Chem. 2012, 51, 3827-3839. (g) Dolinar, B. S.; Gómez-Coca, S.; Alexandropoulos, D. I.; Dunbar, K. R. An air stable radical-bridged dysprosium single molecule magnet and its neutral counterpart: redox switching of magnetic relaxation dynamics. Chem. Commun. 2017, 53, 2283-2286. (h) Alexandropoulos, D. I.; Dolinar, B. S.; Vignesh, K. R.; Dunbar, K. R. Putting a New Spin on Supramolecular Metallacycles: $\mathrm{Co}_{3}$ Triangle and $\mathrm{Co}_{4}$ Square Bearing Tetrazine-Based Radicals as Bridging Ligands. J. Am. Chem. Soc. 2017, 139, 11040-11043.

(2) (a) Demir, S.; Zadrozny, J. M.; Nippe, M.; Long, J. R. Exchange Coupling and Magnetic Blocking in Bipyrimidyl Radical-Bridged Dilanthanide Complexes. J. Am. Chem. Soc. 2012, 134, 18546-18549. (b) Jeon, I.-R.; Park, J. G.; Xiao, D. J.; Harris, T. D. An Azophenine Radical-Bridged $\mathrm{Fe}_{2}$ Single-Molecule Magnet with Record Magnetic Exchange Coupling. J. Am. Chem. Soc. 2013, 135, 16845-16848.

(3) Manriquez, J. M.; Yee, G. T.; McLean, R. S.; Epstein, A. J.; Miller, J. S. A Room-Temperature Molecular/Organic-Based Magnet. Science 1991, 252, 1415-1417.

(4) Caneschi, A.; Gatteschi, D.; Lalioti, N.; Sangregorio, C.; Sessoli, R.; Venturi, G.; Vindigni, A.; Rettori, A.; Pini, M. G.; Novak, M. A. Cobalt(II)-Nitronyl Nitroxide Chains as Molecular Magnetic Nanowires. Angew. Chem., Int. Ed. 2001, 40, 1760-1763.

(5) Pierpont, C. G.; Lange, C. W. The Chemistry of Transition Metal Complexes Containing Catechol and Semiquinone Ligands. In Prog. Inorg. Chem.; John Wiley \& Sons, Inc., 2007; pp 331-442.

(6) (a) Kaizaki, S. Coordination effects of nitroxide radicals in transition metal and lanthanide complexes. Coord. Chem. Rev. 2006, 250, 1804-1818. (b) Gass, I. A.; Tewary, S.; Rajaraman, G.; Asadi, M.; Lupton, D. W.; Moubaraki, B.; Chastanet, G.; Létard, J.-F.; Murray, K. S. Solvate-Dependent Spin Crossover and Exchange in Cobalt(II) Oxazolidine Nitroxide Chelates. Inorg. Chem. 2014, 53, 5055-5066.

(7) Brook, D. J. R. Coordination Chemistry of Verdazyl Radicals. Comments Inorg. Chem. 2015, 35, 1-17.

(8) Ratera, I.; Veciana, J. Playing with organic radicals as building blocks for functional molecular materials. Chem. Soc. Rev. 2012, 41, 303-349.

(9) Kaim, W.; Fees, J. The New Tetrafunctional Pi-acceptor Ligand 3,6-bis (2'-pyrimidyl)-1,2,4,5-tetrazine (bmtz) - Diruthenium Complexes of bmtz and of its 1,4-Dihydro Form. Z. Naturforsch. B Chem. Sci. 1995, 50, 123-127.

(10) (a) Glockle, M.; Hubler, K.; Kummerer, H. J.; Denninger, G.; Kaim, W. Dicopper(I) complexes with reduced states of 3,6-bis $\left(2^{\prime}\right.$ pyrimidyl)-1,2,4,5-tetrazine: Crystal structures and spectroscopic properties of the free ligand, a radical species, and a complex of the 1,4-dihydro form. Inorg. Chem. 2001, 40, 2263-2269. (b) Giles, I. D.; Chifotides, H. T.; Shatruk, M.; Dunbar, K. R. Anion-templated selfassembly of highly stable $\mathrm{Fe}(\mathrm{II})$ pentagonal metallacycles with short anion-pi contacts. Chem. Commun. 2011, 47, 12604-12606. (c) Chainok, K.; Neville, S. M.; Forsyth, C. M.; Gee, W. J.; Murray, K. S.; Batten, S. R. Supramolecular architecture of silver(I) coordination polymers containing polydentate $\mathrm{N}$-donor ligands. CrystEngComm 2012, 14, 3717-3726. (d) Safin, D.; Pialat, A.; Leitch, A. A.; Tumanov, N. A.;
Korobkov, I.; Filinchuk, Y.; Brusso, J. L.; Murugesu, M. "Anion-induced $\mathrm{Ag}(\mathrm{I})$ self assemblies with electron deficient aromatic ligands: anion- $\pi$ system interactions as a driving force for templated coordination networks.". Chem. Commun. 2015, 51, 9547-9550.

(11) Glockle, M.; Kaim, W.; Fiedler, J. Stepwise and chemically reversible reduction of $\left\{(\mu\right.$-bmtz $\left.)\left[\mathrm{MCl}\left(\eta^{6} \text {-cym }\right)\right]_{2}\right\}\left[\mathrm{PF}_{6}\right]_{2}(\mathrm{M}=\mathrm{Ru}, \mathrm{Os}$; bmtz $=3,6$-bis (2'-pyrimidyl)-1,2,4,5-tetrazine) with up to six electrons. Z. Anorg. Allg. Chem. 2001, 627, 1441-1453.

(12) Frantz, S.; Kaim, W.; Fiedler, J.; Duboc, C. Complexes of $\operatorname{Re}(\mathrm{CO})_{3} \mathrm{Cl}$ with different oxidation states of the polyfunctional bmtz/ $\mathrm{H}_{2}$ bmtz ligand system (bmtz $=3$,6-bis(2-pyrimidyl)-1,2,4,5-tetrazine). Inorg. Chim. Acta 2004, 357, 3657-3665.

(13) Woods, T. J.; Ballesteros-Rivas, M. F.; Ostrovsky, S. M.; Palii, A. V.; Reu, O. S.; Klokishner, S. I.; Dunbar, K. R. Strong Direct Magnetic Coupling in a Dinuclear Co ${ }^{\mathrm{II}}$ Tetrazine Radical Single-Molecule Magnet. Chem. - Eur. J. 2015, 21, 10302-10305.

(14) Lemes, M.; Brunet, G.; Pialat, A.; Ungur, L.; Korobkov, I.; Murugesu, M. Strong ferromagnetic exchange coupling in a $\left\{\mathrm{Ni}_{4}{ }_{4}\right\}$ cluster mediated through an air-stable tetrazine-based radical anion. Chem. Commun. 2017, 53, 8660-8663.

(15) Janiak, C. A critical account on pi-pi stacking in metal complexes with aromatic nitrogen-containing ligands. J. Chem. Soc., Dalton Trans. 2000, 3885-3896.

(16) (a) Barclay, T. M.; Hicks, R. G.; Lemaire, M. T.; Thompson, L. K.; $\mathrm{Xu}, \mathrm{Z}$. Synthesis and coordination chemistry of a water-soluble verdazyl radical. structures and magnetic properties of $\mathrm{M}\left(\mathrm{H}_{2} \mathrm{O}\right)_{2}\left(\mathrm{vdCO}_{2}\right)_{2} \cdot 2 \mathrm{H}_{2} \mathrm{O}$ $\left(\mathrm{M}=\mathrm{Co}, \mathrm{Ni} ; \mathrm{vdCO}_{2}=1,5\right.$-dimethyl-6-oxo-verdazyl-3-carboxylate). Chem. Commun. 2002, 1688-1689. (b) Hicks, R. G.; Lemaire, M. T.; Thompson, L. K.; Barclay, T. M. Strong Ferromagnetic and Antiferromagnetic Exchange Coupling between Transition Metals and Coordinated Verdazyl Radicals. J. Am. Chem. Soc. 2000, 122, 80778078. (c) Barclay, T. M.; Hicks, R. G.; Lemaire, M. T.; Thompson, L. K. Verdazyl Radicals as Oligopyridine Mimics: Structures and Magnetic Properties of M(II) Complexes of 1,5-Dimethyl-3-(2,2'-bipyridin-6-yl)6-oxoverdazyl ( $\mathrm{M}=\mathrm{Mn}, \mathrm{Ni}, \mathrm{Cu}, \mathrm{Zn})$. Inorg. Chem. 2003, 42, 22612267. (d) Brook, D. J. R.; Richardson, C. J.; Haller, B. C.; Hundley, M.; Yee, G. T. Strong ferromagnetic metal-ligand exchange in a nickel bis(3,5-dipyridylverdazyl) complex. Chem. Commun. 2010, 46, 65906592. (e) Eberle, B.; Damjanović, M.; Enders, M.; Leingang, S.; Pfisterer, J.; Krämer, C.; Hübner, O.; Kaifer, E.; Himmel, H.-J. Radical Monocationic Guanidino-Functionalized Aromatic Compounds (GFAs) as Bridging Ligands in Dinuclear Metal Acetate Complexes: Synthesis, Electronic Structure, and Magnetic Coupling. Inorg. Chem. 2016, 55, 1683-1696.

(17) Becke, A. D. Density functional thermochemistry. III. The role of exact exchange. J. Chem. Phys. 1993, 98, 5648-5652.

(18) Ruiz, E. Theoretical Study of the Exchange Coupling in Large Polynuclear Transition Metal Complexes Using DFT Methods. In Principles and Applications of Density Functional Theory in Inorganic Chemistry II; Kaltsoyannis, N., McGrady, J. E., Eds.; Springer: Berlin, 2004; pp 71-102.

(19) (a) Vignesh, K. R.; Langley, S. K.; Murray, K. S.; Rajaraman, G. What Controls the Magnetic Exchange Interaction in Mixed- and Homo-Valent $\mathrm{Mn}_{7}$ Disc-Like Clusters? A Theoretical Perspective. Chem. - Eur. J. 2015, 21, 2881-2892. (b) Fohlmeister, L.; Vignesh, K. R.; Winter, F.; Moubaraki, B.; Rajaraman, G.; Pottgen, R.; Murray, K. S.; Jones, C. Neutral diiron(III) complexes with $\mathrm{Fe}_{2}(\mu \text {-E })_{2}(\mathrm{E}=\mathrm{O}, \mathrm{S}, \mathrm{Se})$ core structures: reactivity of an iron(I) dimer towards chalcogens. Dalton Trans. 2015, 44, 1700-1708. (c) Rajeshkumar, T.; Rajaraman, G. Is a radical bridge a route to strong exchange interactions in lanthanide complexes? A computational examination. Chem. Commun. 2012, 48, $7856-7858$

(20) Singh, S. K.; Gupta, T.; Badkur, P.; Rajaraman, G. Magnetic Anisotropy of Mononuclear $\mathrm{Ni}^{\mathrm{iI}}$ Complexes: On the Importance of Structural Diversity and the Structural Distortions. Chem. - Eur. J. 2014, 20, 10305-10313. 